\title{
TeMPerature MeAsurements in A PUMP CYLINDER BLOCK
}

\author{
Zloto, T.; Wolny, R. \& Rygallo, A.
}

Abstract: A method for temperature measurement in the cylinder block of a piston axial pump is presented. The method employs an electronic measuring system with an optoelectronic sensor, designed be the authors. The functioning principle and the component subsystems of the measuring system are discussed. The results of measuring temperature increments in the kinematical pair piston - cylinder, depending on the operation parameters of the pump, are presented. The developed measuring system can be an alternative solution to the existing systems. The aim of the research is also to examine the influence of clearance in the kinematic pair: piston - cylinder block on thermal heating in the pump.

Key words: temperature measurement, hydraulic stand, optoelectronic sensor, piston pump
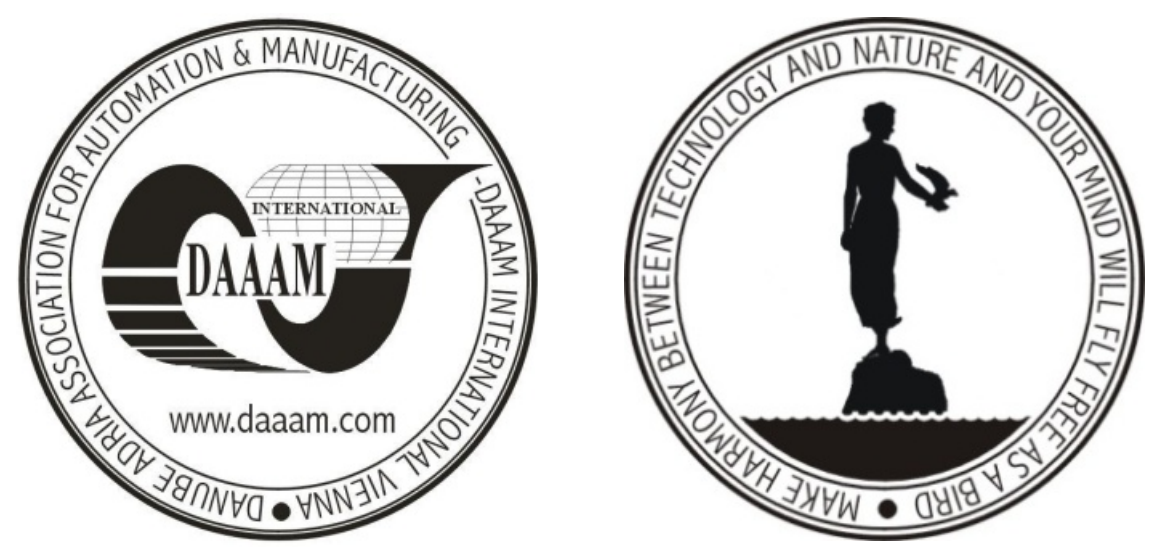

Authors' data: Prof. Zloto, T[adeusz]; Dr. Wolny, R[yszard]; Dr. Rygallo, A[ndrzej], Technical University of Czestochowa, Dabrowskiego 69, 42-200 Czestochowa, Poland, zlotot@o2.pl, rwolny@itm.pcz.pl, andryg@pro.onet.pl

This Publication has to be referred as: Zloto, T[adeusz]; Wolny, R[yszard] \& Rygallo, A[ndrzej] (2009). Temperature Measurements in a Pump Cylinder Block, Chapter 84 in DAAAM International Scientific Book 2009, pp. 873-880, B. Katalinic (Ed.), Published by DAAAM International, ISBN 978-3-901509-69-8, ISSN 17269687, Vienna, Austria

DOI: $10.2507 /$ daaam.scibook.2009.84 